\title{
Influência do sistema de alojamento no comportamento e bem-estar de matrizes suínas em gestação
}

\author{
Iran José Oliveira da Silva ${ }^{1}$, Héliton Pandorfi ${ }^{2}$, Sônia Maria de Stefano Piedade ${ }^{3}$ \\ ${ }^{1}$ Departamento de Engenharia Rural, NUPEA - ESALQ/USP, Av. Pádua Dias, 11, CEP: 13418-900, Piracicaba, SP. Tel.: (19)3429-4217. r.238. \\ 2 Departamento de Tecnologia Rural, UFRPE. \\ ${ }^{3}$ Departamento de Ciências Exatas, ESALQ/USP, Piracicaba, SP.
}

RESUMO - Esta pesquisa foi desenvolvida no setor de gestação, com 24 matrizes primíparas, 12 fêmeas alojadas em baias individuais e 12 animais em baias coletivas, para avaliar diferentes sistemas de alojamento (baias individuais e baias coletivas) para matrizes gestantes, visando caracterizar aspectos quantitativos e qualitativos do ambiente e as variáveis que influenciam o sistema de produção. O trabalho foi dividido em duas etapas em função da forma de avaliação dos dados: análise bioclimática e análise dos sistemas de alojamento. A avaliação bioclimática foi realizada por meio do registro dos elementos meteorológicos, na sala de gestação e no ambiente externo. Nos sistemas de alojamento, foram avaliados as relações comportamentais, os parâmetros fisiológicos e os índices zootécnicos. O delineamento experimental foi em blocos casualizados, com dois sistemas de alojamento e 67 blocos. As características ambientais apontam o sistema de alojamento em baias coletivas como aquele que permitiu melhor condicionamento térmico natural às matrizes em gestação. Os parâmetros fisiológicos e os índices zootécnicos apresentaram valores mais adequados para o sistema de alojamento em baias coletivas, assim como seu reflexo no desempenho da parição dos leitões. A avaliação comportamental, realizada pelo monitoramento por meio do registro de imagens de vídeo, apontou menor incidência de comportamentos resultantes do estresse ambiental, estereotipias e interações agressivas no sistema de alojamento em baias coletivas.

Palavras-chave: bem-estar, comportamento animal, conforto térmico das construções

\section{Effect of housing system on the behavior and welfare for pregnant sows}

ABSTRACT - This research was carried out in the gestation facility, with 24 gilts, 12 females housed in individual cages and 12 housed in collective pens, to evaluate different housing systems (individual cages, collective pens) for pregnant sows, aiming to describe quantitative and qualitative aspects of environment and the characteristics that influence the production system. This work was divided in two stages in function of the way chose for data analysis: bioclimatic and housing system analysis. Bioclimatic evaluation was realized by registering meteorological elements, inside gestation room and in external environment. Housing system evaluation was realized by behavioral relationships, physiological parameters and productive indexes. A completely randomized blocks design was used, with two housing system and 67 blocks. The environmental characteristics pointed the collective pens housing system as the one that permitted better natural thermal conditioning for pregnant gilts. Physiological characteristics and productive indexes showed more adequate values for collective pens housing system, as well as its consequence in the farrowing performance of the pigs. Behavior evaluation, performed by image monitoring using video cameras, showed lower incidence of behaviors resulting of environmental stress, stereotypes and aggressive interactions in collective pens housing system.

Key Words: animal behavior, thermal comfort of buildings, welfare

\section{Introdução}

O conceito de bioclimatologia é amplo, uma vez que inclui todas as condições que afetam o desenvolvimento dos animais, envolvendo aspectos fisiológicos e ambientais (Curtis \& Backstrom, 1992).

A temperatura ambiente considerada ótima para a ma triz varia entre 7 e $23^{\circ} \mathrm{C}$ (Noblet et al., 1989; Yan et al., 2000;
Brown-Brandl et al., 2001). Nas matrizes, as altas temperaturas no interior das instalações influenciam negativamen tea eficiência reprodutiva. Em locais onde as temperaturas no verão foram superiores a $24^{\circ} \mathrm{C}$, verificaram-se diminuição da fertilidade das fêmeas suínas, alta porcentagem de retorno ao cio (Love et al., 1995; Peltoniemi et al., 1999; Nunes et al., 2003) principalmente nas fêmeas primíparas (Vieira \& Vieira, 1987), atraso da maturidade sexual (Perez y Perez \& 
Guitierrez, 1987; Flores et al., 1989) e maior mobilização de gordura corporal durante a lactação (Barb et al., 1991). Ao contrário, em regiões onde os dias quentes não ultrapassaram a temperatura de $24^{\circ} \mathrm{C}$, não foram observados efeitos significativos sobre a fertilidade e taxa de concepção das fêmeas (Love et al., 1993).

A criação intensiva ou industrial, em que o animal permanece durante toda a sua vida em instalações fechadas, muitas vezes isolado dos outros suínos e em espaço reduzido, alterou drasticamente as suas formas normais de comportamento, criando diversas situações de estresse. Isto posto, a avaliação do bem-estar animal na exploração agropecuária pode envolver aspectos ligados às instalações, ao manejo e ao ambiente, como a distribuição de água e comida, existência de camas, possibilidade de movimento, descanso, contato entre animais, reprodução, temperatura, ventilação, luz, espaço disponível ou piso (Anil et al., 2002;

Bauer \& Hoy, 2002; O’Connell et al., 2004).

O objetivo geral nesta pesquisa consiste na avaliação de diferentes sistemas de alojamento para matrizes gestantes, visando caracterizar aspectos quantitativos e qualitativos do ambiente e as variáveis que influenciam o sistema de produção. Os objetivos específicos são a análise da interrelação animal e ambiente, sob o ponto de vista bioclimático, verificando as influências dos elementos meteorológicos e seus reflexos no conforto animal, a eficiência de diferentes sistemas de alojamento de matrizes em baias individuais e coletivas, visando ao estudo do comportamento animal, e seus reflexos nos parâmetros fisiológicos e índices zootécnicos.

\section{Material e Métodos}

O experimento foi realizado em uma granja comercial, cuja principal atividade é a produção industrial de suínos, localizada no município de Elias Fausto, SP, hoje um laboratório experimental do NAP - NUPEA/USP, apresentando latitude de $22^{\circ} 36^{\prime} \mathrm{S}$, longitude de $47^{\circ} 36^{\prime} \mathrm{W}$ e altitude de $535 \mathrm{~m}$. O clima da região é caracterizado como mesotérmico Cwa (tropical de altitude), com temperatura do mês mais frio entre 3 e $18^{\circ} \mathrm{C}$, com inverno seco, e temperatura do mês mais quente maior que $22^{\circ} \mathrm{C}$, segundo classificação Köppen (Pereira et al., 2002).

O desenvolvimento da pesquisa foi na fase de gestação, no período de 4/1/2005 a 11/3/2005, com duração média de 67 dias. O experimento foi dividido em duas etapas, em função da forma de avaliação dos dados: análise bioclimática e análise dos sistemas de alojamento. Foram avaliados dois sistemas de alojamento, em baias individuais de gestação e em baias coletivas.
A instalação referente ao alojamento das matrizes gestantes é caracterizada tipologicamente por $60,0 \mathrm{~m}$ de comprimento por 15,0 $\mathrm{m}$ de largura, pé direito de 2,3 $\mathrm{m}$, beiral de $0,5 \mathrm{~m}$ e orientação leste-oeste. Cobertura com telhas de cerâmica do tipo francesa, sem a presença de forro de revestimento, sendo que o sentido longitudinal da instalação apresenta fechamento lateral em alvenaria, com peitoril de $1,10 \mathrm{~m}$, totalizando uma área de abertura lateral de $144 \mathrm{~m}^{2}$.

As baias individuais de contenção (1,95 m de comprimento $\mathrm{x}$ 0,60 m de largura x 1,20 m de altura, totalizando uma área de $1,17 \mathrm{~m}^{2}$, com volume de $1,40 \mathrm{~m}^{3}$ ) apresentava piso concretado, vazado no terço final. Esse sistema de alojamento também dispunha de um sistema de resfriamento evaporativo compostos por quatro linhas de nebulização e ventilação forçada, acionados manualmente quando a temperatura ambiente excedia os $30^{\circ} \mathrm{C}$.

As baias coletivas apresentavam as seguintes dimensões: 4,80 m de comprimento, por 2,80 $\mathrm{m}$ de largura e muretas de contenção de $1,10 \mathrm{~m}$ de altura, dispondo no terço final da baia um ripado de bambu, de maneira a garantir sombreamento aos animais, como medida de proteção a possíveis doenças de pele, resultantes da exposição direta à radiação solar. Além disso, possui piso concretado sem substrato ou cama disponível, totalizando uma área livre de 13,44 $\mathrm{m}^{2}$, dispondo de $2,24 \mathrm{~m}^{2}$ por animal.

O estudo foi realizado com animais da raça característica da granja (Landrace e Large White) e fêmeas de genética própria da granja, resultante do cruzamento das matrizes avós e machos híbridos comerciais (PIC-412 Agroceres). As matrizes selecionadas eram de mesma ordem de parto, com o objetivo de eliminar fatores de interferência, habilidade materna, número de leitões/ leitegada. Foram selecionadas 12 marrãs para observação no sistema de alojamento em baias individuais de gestação e 12 em baias coletivas, divididas em dois grupos de seis animais, totalizando 24 primíparas para comparação dos sistemas de criação.

Foram monitoradas as variáveis meteorológicas na sala de gestação e no ambiente externo, em intervalos de 15 minutos, por meio de data logger da marca Hobo, modelo H08-00X-02, instalados em pontos estratégicos no interior da instalação, e no ambiente externo, permitindo o registro de dados: temperatura de bulbo seco (Ts), umidade relativa do ar (UR), temperatura de ponto de orvalho (Tpo), temperatura de globo negro (Tg) e umidade absoluta (UA).

Para determinação da eficiência térmica das instalações, com os dados referentes às variáveis meteorológicas registradas nos ambientes estudados, foram determinados o índice de temperatura de globo e umidade (ITGU) e a 
entalpia específica $\mathrm{h}\left(\mathrm{kJ} . \mathrm{kg}^{-1}\right)$ por meio das seguintes equações:

a) índice de temperatura de globo e umidade (ITGU), proposto por Buffington et al. (1981):

$$
I T G U=T g+0,36 T p o-330,08
$$

em que: $T g=$ temperatura de globo negro $(\mathrm{K})$ e $T p o=$ temperatura de ponto de orvalho $(\mathrm{K})$;

b) entalpia (kJ.kg ar $\left.\operatorname{seco}^{-1}\right)$, proposta por Albright (1990):

$$
H=1,006 T s+W(2501+1,805 T s)
$$

em que: $T s=$ temperatura de bulbo seco $\left({ }^{\circ} \mathrm{C}\right)$ e $W=$ razão de mistura ( $\mathrm{kg}$ vapor d'água.kg ar $\left.\mathrm{seco}^{-1}\right)$.

Como variáveis-resposta a esses sistemas de alojamento, foram avaliados os índices zootécnicos e as relações comportamentais e fisiológicas.

O registro das imagens, para posterior análise comportamental, foi realizado por meio de oito microcâmeras coloridas (sistema NTSC) analógicas de 300 linhas horizontais de definição, com sensibilidade mínima de 1 lux, $12 \mathrm{~V}$ de tensão a $180 \mathrm{~mA}$ e lente convergente de 2,45 mm.

As imagens foram registradas semanalmente, totalizando nove dias de observação, das 7 às $18 \mathrm{~h}$, possibilitando gravação contínua das imagens durante todo período de observação, sendo gerenciadas pelo software “TOPWAY”, armazenando as informações em um banco de dados para posterior análise. No entanto, para critério de análise das imagens, foram estabelecidos horários de observação, das 8 às 9h, das 12 às $13 \mathrm{~h}$ e das 16 às $17 \mathrm{~h}$, totalizando três horas de observação para os dias selecionados em intervalos de 4 minutos entre as composições de imagens, de acordo com observações prévias que caracterizaram extensos períodos de inatividade dos animais, sem que houvesse variação comportamental que pudesse ser identificada, na qual foram selecionados aleatoriamente seis animais de cada tratamento (Rudkin \& Stewart, 2003). As matrizes foram devidamente identificadas com numeração no dorso, variando de 1 a 12 para os seus respectivos sistemas de alojamento, o que possibilitou a individualização de cada animal no momento da análise das imagens.

A temperatura retal e a taxa respiratória das matrizes foram registradas semanalmente, às 9, 12 e 17 h, caracterizando as respostas fisiológicas nos períodos de baixa e alta radiação. As medidas de temperatura foram tomadas com auxílio de um termômetro digital, Digi Sense, modelo 852210 , e a taxa respiratória, por observação visual direta e quantificação dos movimentos do flanco por minuto, por meio de um cronômetro digital. Os animais foram selecionados para as avaliações de maneira aleatória, perfazendo uma amostragem de seis matrizes em cada um dos sistemas de alojamento.

Todos os índices zootécnicos que compunham o con trole experimental foram fornecidos pela própria granja. Por meio do programa de rastreabilidade foi possível localizar cada animal individualmente, bem como seus índices de produção, no setor de gestação e, na fase subseqüente, na maternidade.

As fêmeas foram cobertas a partir dos 6 meses de idade $( \pm 130 \mathrm{~kg})$, alojadas em grupo até a detecção de cio, quando foram recolhidas e inseminadas em baias individuais, onde permaneceram por 45 dias, e posteriormente distribuídas de forma aleatória nos respectivos sistemas de alojamento.

Uma ração à base de milho e sorgo, capaz de fornecer $3.250 \mathrm{kcal} \mathrm{EM} / \mathrm{dia}$, foi formulada segundo recomendações do NRC (1998) e distribuída na base de $2,0 \mathrm{~kg} /$ dia do 10 ao $30 \underline{\mathrm{o}} \mathrm{dia} ; 2,2 \mathrm{~kg} / \mathrm{dia}$ do $31 \underline{\mathrm{o}}$ ao $85 \underline{\mathrm{o}} \mathrm{dia} ; 3,0 \mathrm{~kg} / \mathrm{dia}$ do $86 \underline{\mathrm{o}}$ ao $110 \underline{\mathrm{o}}$ e $2,0 \mathrm{~kg} / \mathrm{dia}$ do 111 o ao 114 o dia de gestação, fornecida uma única vez ao dia, às $7 \mathrm{~h}$.

$\mathrm{O}$ delineamento experimental adotado para análise geral foi em blocos casualizados (DBC), adotando-se como tratamentos os sistemas de alojamento em baias de gestação individuais e coletivas e 67 blocos. As variáveis meteorológicas e ambientais e os parâmetros fisiológicos foram analisados adotando-se o DBC para análise geral e o teste de Tukey para a comparação entre as médias.

As variáveis comportamentais foram submetidas à análise de freqüência, adotando-se o programa estatístico Statistical Analysis System (SAS, 1992).

Para análise dos índices zootécnicos, adotou-se o delineamento inteiramente casualizado (DIC) com dois tratamentos e 12 repetições, utilizando-se o teste Tukey para comparação entre as médias.

\section{Resultados e Discussão}

Os resultados médios diários das variáveis-resposta da subdivisão do microambiente estudado (sala de gestação) e seus respectivos sistemas de alojamento, baias individuais e coletivas foram obtidos a partir da comparação entre os sistemas de alojamento e o ambiente externo (Tabela 1). Verificou-se que os sistemas de alojamento apresentaram diferenças para temperatura de bulbo seco (Tbs), quando comparados entre si, observando-se o maior valor de temperatura no sistema em baias individuais, em virtude do maior número de animais alojados ( animal $\mathrm{m}^{-2}$ ) neste sistema de alojamento, e pelo aporte de energia gerado pelos animais. O sistema em baias coletivas apresentou menor valor de Tbs comparativamente ao sistema em baias individuais, 
Tabela 1 - Variáveis ambientais para o sistema de alojamento em baias individuais (BI), baias coletivas (BC) e no ambiente externo

\begin{tabular}{lccccc}
\hline Sistema de alojamento & Tbs $\left({ }^{\circ} \mathrm{C}\right)$ & UR $(\%)$ & Tg $\left({ }^{\circ} \mathrm{C}\right)$ & ITGU & h $\left(\mathrm{kJ}^{\circ} \mathrm{kg}^{-1}\right)$ \\
\hline BI & $25,47 \mathrm{a}$ & $70,48 \mathrm{~b}$ & $25,20 \mathrm{a}$ & $73,40 \mathrm{a}$ & $63,47 \mathrm{a}$ \\
BC & $25,03 \mathrm{~b}$ & $70,14 \mathrm{~b}$ & $25,20 \mathrm{a}$ & $73,56 \mathrm{a}$ & $62,02 \mathrm{~b}$ \\
Externo & $24,48 \mathrm{c}$ & $79,65 \mathrm{a}$ & $24,97 \mathrm{a}$ & $73,46 \mathrm{a}$ & $63,51 \mathrm{a}$ \\
\hline
\end{tabular}

Médias com letras diferentes, na mesma coluna, diferem $(\mathrm{P}<0,01)$ pelo teste Tukey.

Tbs = temperatura de bulbo seco, UR = umidade relativa do ar, $\mathrm{Tg}=$ temperatura de globo negro, ITGU = índice de temperatura de globo e umidade.

fato atribuído à própria disposição das baias coletivas que ficavam sujeitas à maior renovação de ar, pois estavam localizadas na face sul da sala de gestação.

Com relação à umidade relativa do ar (UR) e à temperatura de globo negro (Tgn), ambas as variáveis não apresentaram diferenças entre baias individuais e coletivas $(\mathrm{P}<0,01)$, no entanto, o ambiente externo foi o que apresentou a maior média para a UR, caracterizando a condição de entorno à instalação.

Os valores médios diários para o índice de temperatura de globo e umidade (ITGU) não mostraram diferenças $(\mathrm{P}<0,01)$, a exemplo das variáveis que integram o modelo Tgn e temperatura de ponto de orvalho (Tpo). Os dados médios para a entalpia $(\mathrm{h})$ apontam diferenças entre os sistemas de alojamento $(\mathrm{P}<0,01)$, verificando-se maior quantidade de energia na parcela de ar referente ao sistema de alojamento em baias individuais, apresentando valor próximo àquele registrado no ambiente externo.

Há evidência do efeito da temperatura nos diferentes sistemas de alojamento, baias coletivas e individuais e no ambiente externo (Figura 1). Nestas condições, verifica-se que o condicionamento térmico no interior da instalação esteve acima da condição recomendada, onde a temperatura ambiente considerada ótima para a matriz varia entre 7 e $23^{\circ} \mathrm{C}$ (Noblet et al., 1989) ficando evidente que a condição de conforto proporcionada aos animais está inadequada, pois verifica-se que, no decorrer do período avaliado, a temperatura média diária esteve a maior parte do tempo superior aos $23^{\circ} \mathrm{C}$, caracterizando-se como uma situação de alerta a possíveis problemas reprodutivos, principalmente em fêmeas primíparas (Love et al., 1995; Peltoniemi et al., 1999; Nunes et al., 2003). Observa-se que, durante o estudo, as temperaturas médias mantiveram-se próximas à faixa de conforto dos animais, entre 23 e $24^{\circ} \mathrm{C}$, em apenas $18 \%$ do tempo total de registro para ambos os sistemas de alojamento (Figura 1). No entanto, a temperatura manteve-se, durante toda a fase avaliada, abaixo da temperatura crítica superior (TCS), não atingindo, em média, $28^{\circ} \mathrm{C}$ (Mount, 1968; Curtis, 1983; Silva, 1999), promovendo condições inadequadas, em que os animais submetidos a esses ambientes passariam a sofrer estresse calórico e reflexo direto na manutenção dos proces sos reprodutivos.
Na tentativa de evidenciar o efeito do condicionamento térmico das matrizes, foram selecionados os dias críticos do período estudado, que apresentaram maior (25/02) e menor (28/01) valor para entalpia (Moura et al., 1997). Desta forma, verifica-se que, das 11 às $19 \mathrm{~h}$ a temperatura no interior da sala de gestação esteve acima da TCS para o sistema de alojamento em baias coletivas, atingindo um pico de temperatura às $16 \mathrm{~h}$, quando se registrou $32,86^{\circ} \mathrm{C}$ (Figura 2a).

No que se refere às baias individuais, observa-se que das 11 às $19 \mathrm{~h}$ a temperatura apresentou pequenas oscilações frente à linha da TCS, mostrando-se sempre inferior àquela registrada nas baias coletivas (Figura 2a). Esta variação é o resultado da modificação do ambiente, em virtude do uso de um recurso de resfriamento, posto que a instalação dispunha de uma linha de nebulização para os animais alojados nas baias individuais, que era acionada sempre que a temperatura excedia os $30^{\circ} \mathrm{C}$, reduzindo o efeito do ambiente térmico sobre as matrizes.

A temperatura máxima registrada nas baias coletivas foi de $32,86^{\circ} \mathrm{C}$ e a mínima, de $22,09^{\circ} \mathrm{C}$ (Figura 2a), resultando em uma amplitude de $10,70^{\circ} \mathrm{C}$. De maneira análoga, têm-se, para as baias individuais, temperaturas máxima e mínimade 31,02 e $23,05^{\circ} \mathrm{C}$, repectivamente, gerando uma amplitudede $7,17^{\circ} \mathrm{C}$, destacando-se o sistema de alojamento em baias individuais como aquele que melhor se adequa às necessidades dos animais, frente à eficiência do sistema de climatização adotado.

A variação da temperatura no decorrer do dia selecionado (28/01) apresentou valores inferiores para as baias coletivas, comparativamente às individuais, evidenciando melhor condicionamento para as baias coletivas, que se mostraram, em média, mais próximas da condição de conforto das matrizes (Figura 2b). Em geral, para os dois sistemas de alojamento, observam-se que ambos mativeram-se dentro da faixa recomendada, de 23 a $28^{\circ} \mathrm{C}$. A amplitude térmica registrada para o dia de menor entalpia foi de $4,99^{\circ} \mathrm{C}$ para as baias coletivas e de $4,82^{\circ} \mathrm{C}$ para as individuais, evidenciando sua redução comparativamente ao dia de maior entalpia, promovendo condição mais propícia aos animais.

Os valores médios da entalpia (h) apresentaram resultados que apontam diferenças $(\mathrm{P}<0,01)$ entre os sistemas de 


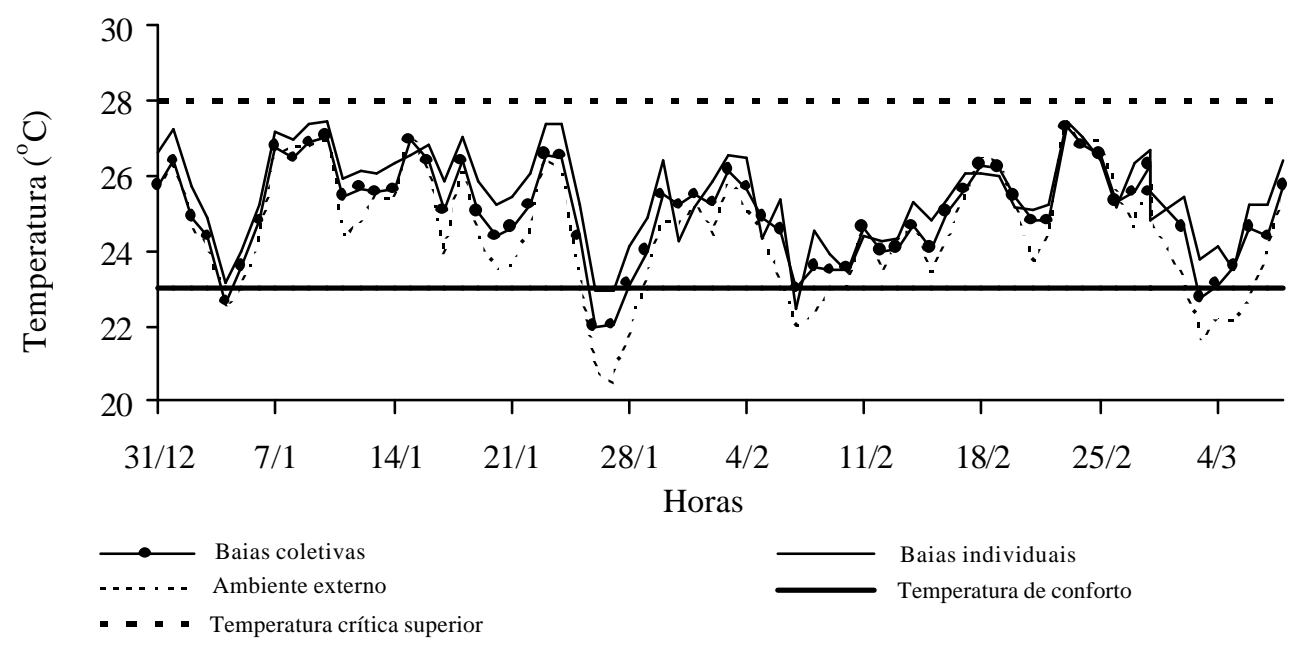

Figura 1 - Variação da temperatura média diária nos diferentes sistemas de alojamento, sala de gestação e no ambiente externo.
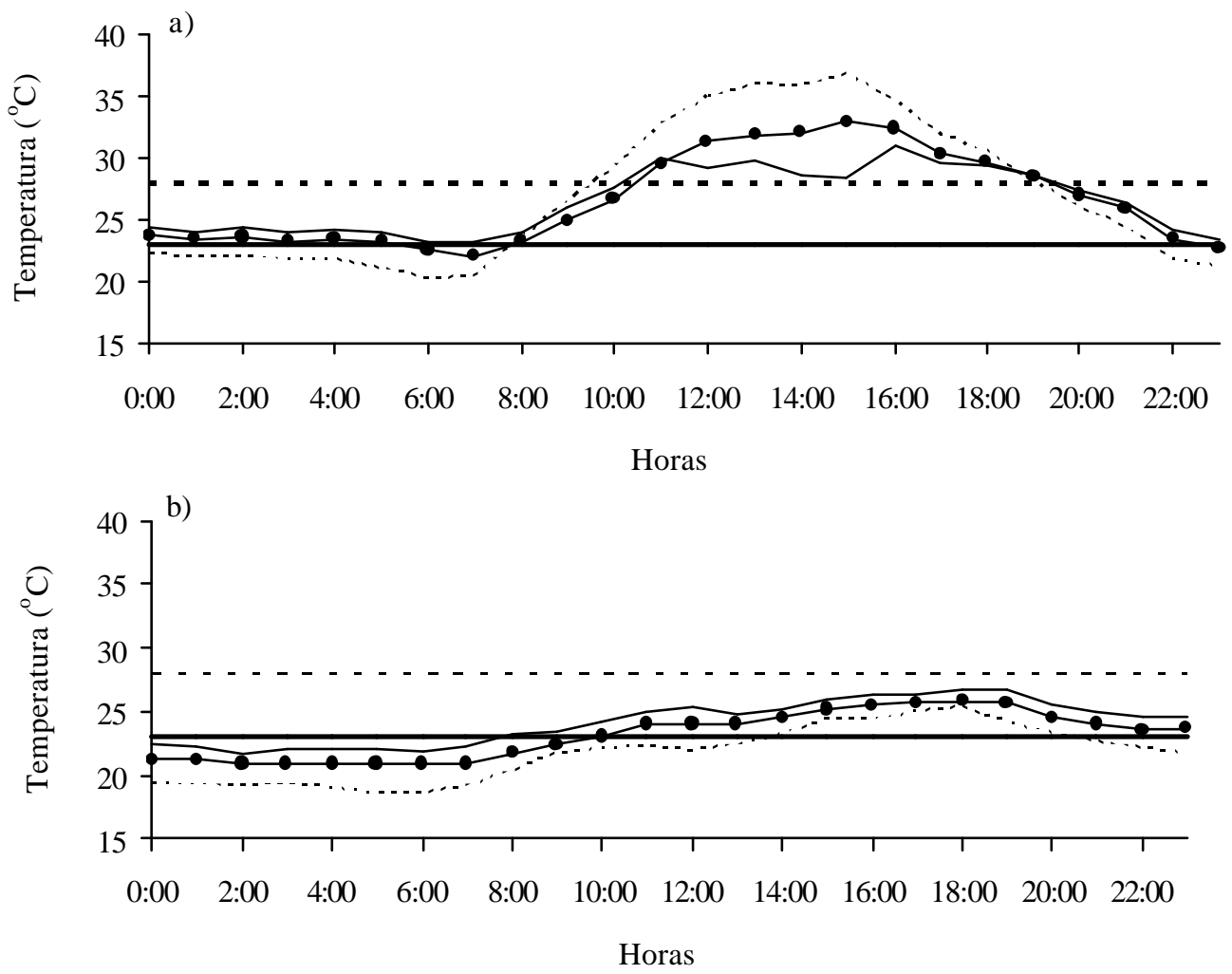

$\longrightarrow$ Baias coletivas $\_$Baias individuais ....... Externo $\longrightarrow$ Temperaturas de conforto _ . . TCS

Figura 2 - Variação da temperatura média horária para os dias críticos de maior (a) e menor (b) entalpia nos diferentes sistemas de alojamento, na sala de gestação e no ambiente externo.

alojamento. O maior valor verificado foi para baias individuais, expressando a quantidade de energia interna da parcela de ar, pontualmente para esta condição no microambiente avaliado, em relação à soma de seus componentes, de uma mistura de ar seco e vapor d'água, considerando-se a $\operatorname{Tbs}\left({ }^{\circ} \mathrm{C}\right)$ e a razão de mistura ( $\mathrm{kg}$ de vapor d'água.kg de ar $\mathrm{seco}^{-1}$ ).

A variação entálpica nos sistemas de alojamento adotados apresentou valor da ordem de 63,47 e 62,02 kJ.kg-1 
no decorrer do período experimental, não excedendo o valor limite para este índice $\left(73,80{\mathrm{~kJ} . \mathrm{kg}^{-1}}^{-1}\right.$ (Figura 3). As aproximações dos valores de entalpia recomendada para os animais foram calculadas com base nas condições de conforto dos animais, considerando-se a temperatura crítica superior de $28^{\circ} \mathrm{C}$ e umidade relativa de $70 \%$. Para o cálculo da entalpia de conforto, adotou-se temperatura de $23^{\circ} \mathrm{C}$ e umidade relativa do ar de 70\%, de acordo com Silva (1999).

A variação da entalpia nos sistemas de alojamento adotados foi muito similar (Figura 4a), estando sempre dentro da faixa estabelecida para o índice, exceto para os horários das 12 às $17 \mathrm{~h}$, em que as baias individuais estiveram ligeiramente acima da faixa ideal, valores esti-

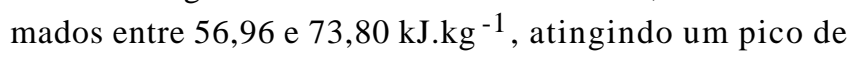
$76,04 \mathrm{~kJ} . \mathrm{kg}^{-1}$, em virtude da utilização do nebulizador. Para o dia de menor disponibilidade de energia no ambiente (Figura 4b), observa-se que o índice de entalpia não excedeu a faixa recomendada, para ambos os sistemas de alojamento.

Considerando-se o microclima proporcionado aos animais nos diferentes sistemas de alojamento (baias individuais e coletivas) influenciados pelas condições externas à instalação, verifica-se que o layout de distribuição dos animais no sistema de alojamento em baias coletivas permitiu melhor condicionamento térmico natural às matrizes em gestação, em razão de sua localização no interior da edificação, que potencializava as trocas convectivas de calor por meio da ventilação natural, do fato de dispor de maior área por animal.

A taxa respiratória apresentou diferença $(\mathrm{P}<, 01)$ entre os sistemas de alojamento, de 43 e 36 mov.min. ${ }^{-1}$ para baias individuais e baias coletivas, respectivamente, mostrando-se acima da condição de conforto para animais desta categoria (Tabela 2). Fêmeas gestantes em condição de conforto térmico apresentam taxa respiratória em torno de 15 a 20 mov.min.-1 . Os movimentos respiratórios podem aumentar de 22 a $100 \%$, em função do ambiente térmico (Manno et al., 2005).

Quando a taxa respiratória está elevada, admite-se que a temperatura do ar está próxima à temperatura corporal, dessa forma, o hipotálamo envia impulso ao sistema cardiorespiratório, na tentativa de eliminar calor por evaporação por meio da respiração.

Com relação à temperatura retal, notam-se diferenças entre os sistemas de alojamento, $38,91^{\circ} \mathrm{C}$ (baias individuais) e $38,72^{\circ} \mathrm{C}$ (baias coletivas), porém, para ambos os sistemas de alojamento a variação da temperatura retal encontra-se próxima à condição de conforto, entre 38,6 e $39,3^{\circ} \mathrm{C}$ (Tabela 2). Para matrizes em gestação, o valor considerado ótimo é de $38,6^{\circ} \mathrm{C}$. Mudanças na temperatura retal são observadas em animais submetidos ao estresse por calor, no entanto, isso ocorre quando o mecanismo de perda de calor evaporativo é insuficiente (Muirhead \& Alexander, 1997).

A modificação do ambiente e a utilização de recursos de resfriamento podem auxiliar a termorregulação animal e reduzir os efeitos do ambiente térmico sobre as respostas fisiológicas. No entanto, o efeito do sistema de nebulização para as baias individuais não foi suficiente para redução da taxa respiratória e da temperatura retal, frente à supressão das matrizes em baias individuais, que promoveram reflexo direto no conforto dos animais, devido ao estresse crônico causado pela restrição de espaço.

A comparação entre as médias observadas nos sistemas de alojamento sobre a resposta aos índices zootécnicos: período de gestação (dias), duração do parto (min), número de leitões nascidos vivos, natimortos e mumificados, peso dos leitões no nascimento $(\mathrm{kg})$, peso no desmame $(\mathrm{kg})$ e

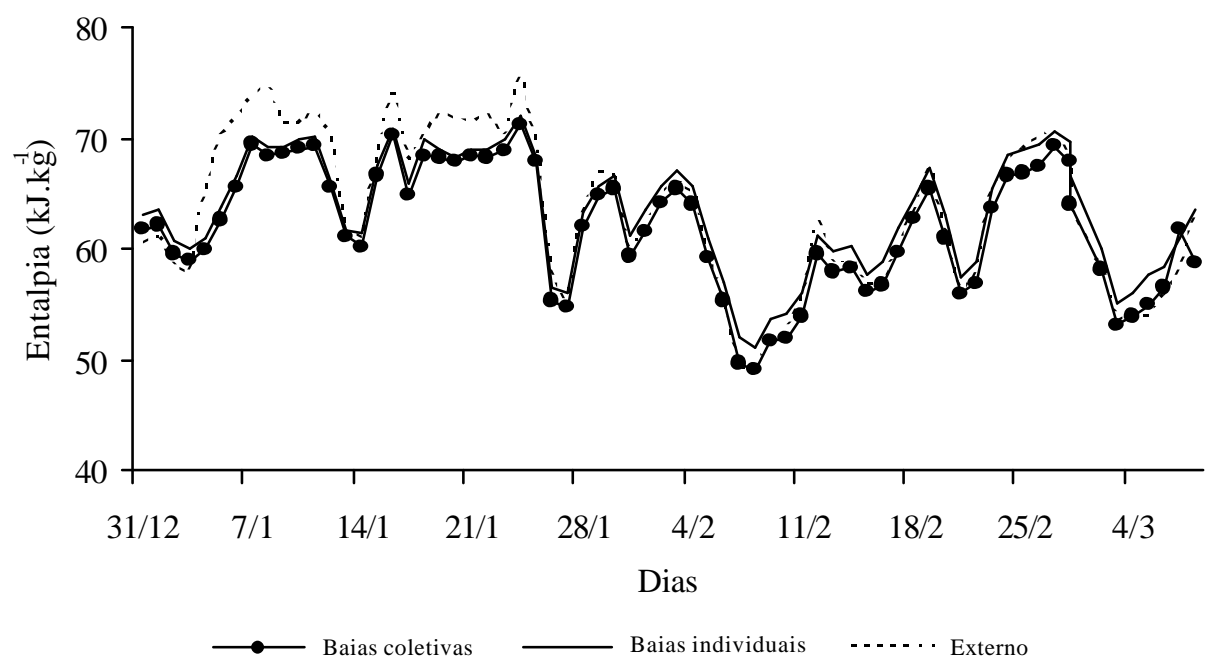

Figura 3 - Variação média diária da entalpia nos diferentes sistemas de alojamento, na sala de gestação e no ambiente externo. 
Tabela 2 - Variáveis fisiológicas no período experimental

\begin{tabular}{lcc}
\hline Sistema de alojamento & Taxa respiratória $\left(\right.$ mov.min.$\left.^{-1}\right)$ & Temperatura retal $\left({ }^{\circ} \mathrm{C}\right)$ \\
\hline Baias individuais & $43 \mathrm{a}$ & $38,91 \mathrm{~b}$ \\
Baias coletivas & $36 \mathrm{~b}$ & $38,72 \mathrm{a}$ \\
\hline
\end{tabular}

Médias com letras diferentes, na coluna, diferem $(P<0,01)$ pelo teste Tukey.

mortalidade não indicou diferenças estatísticas entre os sistemas de alojamento (Tabela 3).

Para efeito de comparação, considera-se um total de 24 matrizes, 12 alojadas em baias individuais e $12 \mathrm{em}$ baias coletivas, e um total de 115 leitões provenientes das fêmeas alojadas em baias individuais e de 131 leitões em baias coletivas. Todos os índices avaliados não apresentaram diferenças estatísticas entre os sistemas de alojamento.

A gestação da fêmea suína tem duração de, aproximadamente, 115 dias (3 meses, 3 semanas e 3 dias), com pequenas variações entre granjas ou raças, para mais ou menos três dias (112 a 118 dias). Nota-se que não houve diferença $(\mathrm{P}<0,01)$ na duração do período de gestação, para
Tabela 3 - Índices zootécnicos na fase de gestação e maternidade para os animais submetidos ao regime de alojamento em baias individuais e coletivas durante a gestação

\begin{tabular}{lcc}
\hline Índice zootécnico & \multicolumn{2}{c}{ Sistema de alojamento } \\
\cline { 2 - 3 } & Baias individuais & Baias coletivas \\
\hline Gestação (dias) & $113,63 \mathrm{a}$ & $113,50 \mathrm{a}$ \\
Duração do parto (min) & $181 \mathrm{a}$ & $152 \mathrm{a}$ \\
Tamanho da leitegada & $9,99 \mathrm{a}$ & $10,99 \mathrm{a}$ \\
Nascidos vivos & $9,58 \mathrm{a}$ & $10,25 \mathrm{a}$ \\
Natimortos & $0,66 \mathrm{a}$ & $0,66 \mathrm{a}$ \\
Mumificados & $0,25 \mathrm{a}$ & $0,08 \mathrm{a}$ \\
Peso no nascimento $(\mathrm{kg})$ & $1,19 \mathrm{a}$ & $1,23 \mathrm{a}$ \\
Peso ao desmame $(\mathrm{kg})$ & $5,11 \mathrm{a}$ & $5,34 \mathrm{a}$ \\
Mortalidade $(\%)$ & $22,54 \mathrm{a}$ & $17,49 \mathrm{a}$ \\
\hline
\end{tabular}

Média com letras diferentes, na linha, diferem $(P<0,01)$ pelo teste Tukey.
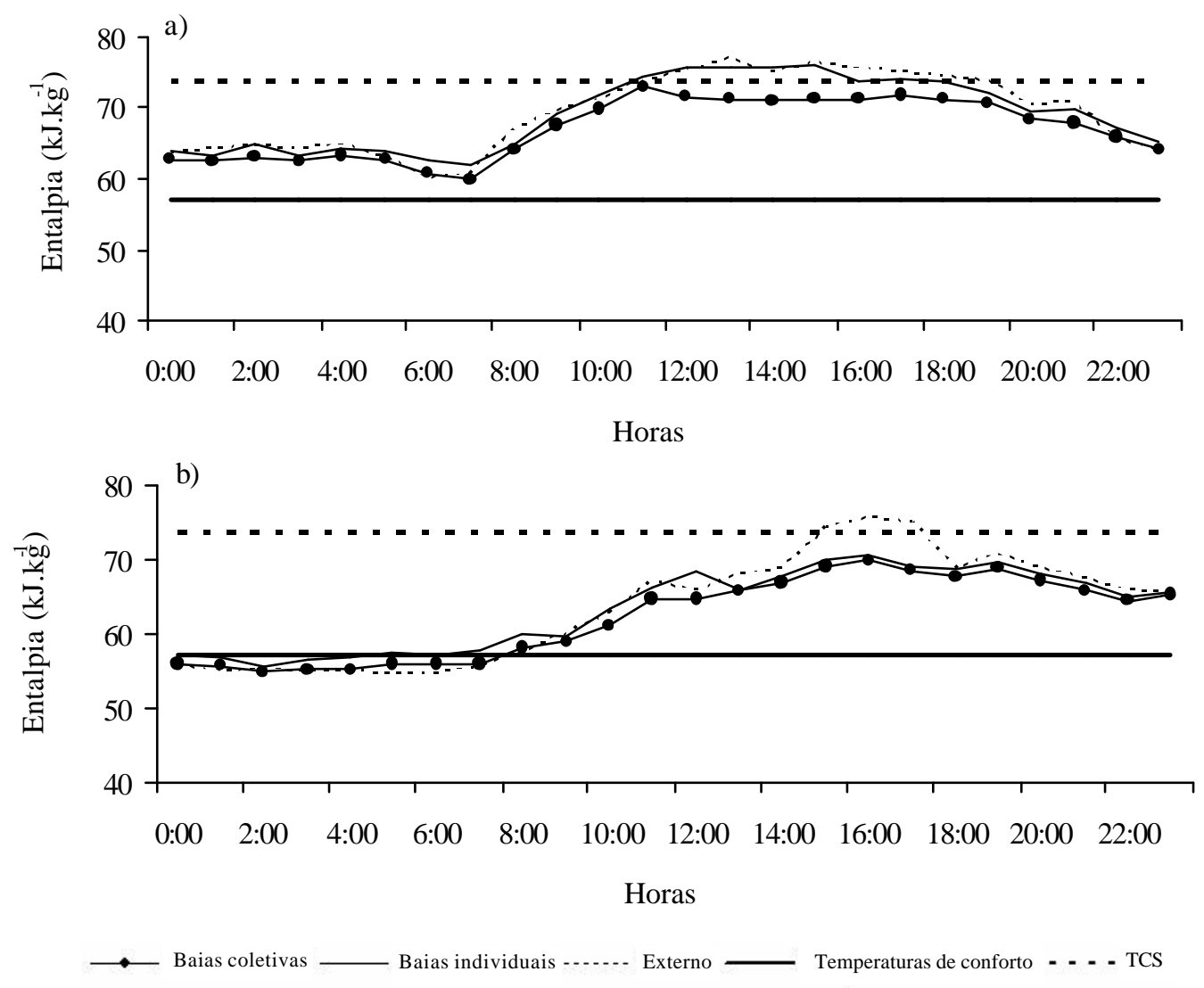

Figura 4 - Variação média horária da entalpia para o dia crítico superior (a) e inferior (b) nos diferentes sistemas de alojamento, na sala de gestação e no ambiente externo. 
os dois sistemas de alojamento (baias individuais e coletivas), de 113,63 e 113,50 dias, respectivamente, encontrando-se dentro dos limites esperados, em que não foram detectadas patologias que pudessem prolongar o período de gestação para ambos os sistemas de alojamentos.

A duração do parto nas fêmeas alojadas em baias individuais mostrou-se superior, quando comparadas às baias coletivas, porém, não-significativa, verificando-se valores médios de 181 e 152 minutos, respectivamente. Quanto maior a duração do parto, maior o número de natimortos (Friend et al., 1962; Cavalcanti et al., 1979). A duração do parto pode ser influenciada negativamente por inúmeros fatores, principalmente o ambiente e o manejo. Assim, altas temperaturas, níveis acentuados de ruídos e demais fatores estressantes tendem a induzir a secreção de adrenalina e de determinadas catecolaminas que bloqueiam a ação da ocitocina, interferindo nas contrações uterinas (Cavalcanti et al., 1979). Porém, todas as fêmeas foram higienizadas e transferidas à maternidade em um período de três dias antes do parto, com o objetivo de reduzir o estresse causado pela mudança do ambiente. Todos os animais foram alojados em uma mesma sala de maternidade em celas individuais, onde a duração do parto, em ambos os sistemas de alojamento, manteve-se próxima da média admitida de 3 horas.

Os dados referentes ao tamanho da leitegada contabilizaram um leitão a mais para o alojamento em baias coletivas, o que pode significar acréscimo de 2.400 animais terminados por ano em relação ao alojamento em baias individuais, gerando uma receita adicional de $\mathrm{R} \$ 449.280,00$, considerando cotação de $\mathrm{R} \$ 2,08 / \mathrm{kg}$ vivo de suíno e peso ao abate de $90 \mathrm{~kg}$.

O número de leitões nascidos vivos apresentou variação entre os sistemas de alojamento, sendo o tamanho da leitegada nas baias individuais de 9,58, ao passo que nas baias coletivas o valor encontrado foi de 10,25 . Os principais fatores que influenciam diretamente o tamanho da leitegada são ordem de parto, idade da matriz na concepção, número de coberturas por cio, época do ano (temperatura e fotoperíodo), nutrição e sanidade (Clark \& Leman, 1986). Admitindo-se que esses fatores de interferência foram controlados, possivelmente essa variação poderia ser atribuída ao estresse crônico causado pela falta de espaço às matrizes em baias individuais de gestação.

Os problemas de má formação (leitões mumificados e natimortos) apresentaram valores de 0,25 mumificados nascidos das matrizes alojadas em baias individuais na fase de gestação e de 0,08 provenientes de matrizes alojadas em baias coletivas. Para os natimortos, verificou-se valor de 0,66 para ambos os sistemas de alojamento.
Tabela 4 - Freqüência e porcentagem média da variação comportamental, atividade, estereotipia, interação social e agressiva das matrizes em sistemas de alojamento em baias individuais e coletivas

\begin{tabular}{|c|c|c|c|}
\hline \multirow[b]{2}{*}{$\begin{array}{l}\text { Freqüência } \\
\text { Porcentagem (\%) }\end{array}$} & \multicolumn{3}{|c|}{ Sistema de alojamento } \\
\hline & Baias individuais & Baias coletivas & Total \\
\hline \multicolumn{4}{|l|}{ Atividade } \\
\hline Inativo & $\begin{array}{c}219 \\
25,35\end{array}$ & $\begin{array}{c}212 \\
24,54\end{array}$ & $\begin{array}{c}431 \\
49,88\end{array}$ \\
\hline Inativo (alerta) & $\begin{array}{c}37 \\
4,28\end{array}$ & $\begin{array}{c}55 \\
6,37\end{array}$ & $\begin{array}{c}92 \\
10,65\end{array}$ \\
\hline Cheirar & $\begin{array}{c}6 \\
0,69\end{array}$ & $\begin{array}{c}15 \\
1,74\end{array}$ & $\begin{array}{c}21 \\
2,43\end{array}$ \\
\hline Beber & $\begin{array}{c}19 \\
2,20 \\
\end{array}$ & $\begin{array}{c}12 \\
1,39 \\
\end{array}$ & $\begin{array}{c}31 \\
3,59 \\
\end{array}$ \\
\hline \multicolumn{4}{|l|}{ Estereotipia } \\
\hline Movimentar a língua & $\begin{array}{c}2 \\
0,23\end{array}$ & $\begin{array}{c}1 \\
0,12\end{array}$ & $\begin{array}{c}3 \\
0,35\end{array}$ \\
\hline Lamber & $\begin{array}{c}22 \\
2,55\end{array}$ & $\begin{array}{c}17 \\
1,97\end{array}$ & $\begin{array}{c}39 \\
4,51\end{array}$ \\
\hline Abrir e fechar a boca & $\begin{array}{c}2 \\
0,23\end{array}$ & $\begin{array}{c}1 \\
0,12\end{array}$ & $\begin{array}{c}3 \\
0,35\end{array}$ \\
\hline Morder & $\begin{array}{c}50 \\
5,79\end{array}$ & $\begin{array}{c}0 \\
0,00\end{array}$ & $\begin{array}{c}50 \\
5,79\end{array}$ \\
\hline Beber & $\begin{array}{c}21 \\
2,43\end{array}$ & $\begin{array}{c}1 \\
0,12\end{array}$ & $\begin{array}{c}22 \\
2,55\end{array}$ \\
\hline Estirar o pescoço & $\begin{array}{c}4 \\
0,46\end{array}$ & $\begin{array}{c}0 \\
0,00\end{array}$ & $\begin{array}{c}4 \\
0,46\end{array}$ \\
\hline Fuçar & $\begin{array}{c}21 \\
2,43 \\
\end{array}$ & $\begin{array}{c}69 \\
7,99 \\
\end{array}$ & $\begin{array}{c}90 \\
10,42 \\
\end{array}$ \\
\hline \multicolumn{4}{|l|}{ Interação social } \\
\hline Lambiscar & $\begin{array}{c}0 \\
0,00\end{array}$ & $\begin{array}{c}2 \\
0,23\end{array}$ & $\begin{array}{c}2 \\
0,23\end{array}$ \\
\hline Cheirar & $\begin{array}{c}26 \\
3,01\end{array}$ & $\begin{array}{c}38 \\
4,40\end{array}$ & $\begin{array}{c}64 \\
7,41\end{array}$ \\
\hline Lamber & $\begin{array}{c}3 \\
0,35 \\
\end{array}$ & $\begin{array}{c}9 \\
1,04 \\
\end{array}$ & $\begin{array}{c}12 \\
1,39 \\
\end{array}$ \\
\hline \multicolumn{4}{|l|}{ Interação agressiva } \\
\hline$\overline{\text { Empurrar }}$ & $\begin{array}{c}0 \\
0,00\end{array}$ & $\begin{array}{c}0 \\
0,00\end{array}$ & $\begin{array}{c}0 \\
0,00\end{array}$ \\
\hline Morder & $\begin{array}{c}0 \\
0,00\end{array}$ & $\begin{array}{c}0 \\
0,00\end{array}$ & $\begin{array}{c}0 \\
0,00\end{array}$ \\
\hline Brigar & $\begin{array}{c}0 \\
0,00\end{array}$ & $\begin{array}{c}0 \\
0,00\end{array}$ & $\begin{array}{c}0 \\
0,00\end{array}$ \\
\hline Perseguir & $\begin{array}{c}0 \\
0,00\end{array}$ & $\begin{array}{c}0 \\
0,00\end{array}$ & $\begin{array}{c}0 \\
0,00\end{array}$ \\
\hline Ameaçar & $\begin{array}{c}0 \\
0,00\end{array}$ & $\begin{array}{c}0 \\
0,00\end{array}$ & $\begin{array}{c}0 \\
0,00\end{array}$ \\
\hline Total & $\begin{array}{c}432 \\
50,00\end{array}$ & $\begin{array}{c}432 \\
50,00\end{array}$ & $\begin{array}{c}864 \\
100,00\end{array}$ \\
\hline
\end{tabular}

Para que um leitão tenha boa possibilidade de desenvolvimento, seu peso mínimo deve ser igual ou superior a $1,2 \mathrm{~kg}$ ou de 0,7 a $1,2 \mathrm{~kg}$, no caso de transferência cruzada de leitões em instalações com grupos de fêmeas, que neste caso possibilitaram a transferência de animais entre as fêmeas de cada um dos sistemas de alojamento estudados. Dessa maneira, a leitegada foi constituída por leitões com peso uniforme, o que lhes permitiu melhor 
desenvolvimento. Neste contexto, verifica-se que o peso ao nascimento médio dos leitões oriundos das fêmeas alojadas em baias individuais de gestação foi de $1,19 \mathrm{~kg} \mathrm{e}$ das matrizes em baias coletivas, de 1,23 kg. Em ambas as situações, nota-se que o ganho de peso médio diário atingiu os valores mínimos exigidos de aproximadamente 0,185 kg.dia ${ }^{-1}$, garantindo desmame aos 21 dias de 5,11 e 5,33 kg para os leitões oriundos de matrizes submetidas às baias individuais e coletivas, respectivamente (Mores et al., 1998).

A mortalidade dos leitões relacionados às matrizes e seus respectivos sistemas de alojamento foi de 22,54 de $17,49 \%$ para baias individuais e coletivas, valores próximos ao valor admitido (25\%) para animais nascidos com peso médio entre 1,1 e 1,2 kg (Mores et al., 1998).

As matrizes submetidas às baias coletivas na fase de gestação tiveram condições de proporcionar melhor desenvolvimento aos leitões, verificando-se índices superiores para peso dos leitões no nascimento e ao desmame e menor mortalidade em relação às matrizes confinadas em baias individuais. Esses acréscimos, embora irrisórios, apontam reflexo direto no cômputo geral da propriedade, garantido o sucesso econômico do negócio, aumentando os lucros e viabilizando as alterações no sistema de alojamento.

A avaliação do bem-estar animal na exploração zootécnica pode envolver aspectos ligados às instalações, ao manejo, ao ambiente e, principalmente, à resposta do animal ao meio no dia-a-dia na unidade de produção, buscando interpretar a linguagem animal, ou seja, a resposta comportamental frente aos regimes de criação.

A inatividade dos animais foi aproximadamente $49,88 \%$ do tempo total de observação (Tabela 4), apresentando pequena diferença entre os sistemas de alojamento, $0,8 \%$ superior para o sistema de alojamento em baias individuais. Com relação aos demais comportamentos que englobam a classe de atividades, verifica-se que os animais alojados em baias coletivas permanecem inativos em alerta $2,08 \%$ acima do tempo de observação dos animais em baias individuais, caracterizando, desta forma, a maior possibilidade de explorar o ambiente, o que se evidencia pelo ato de cheirar o piso realizando movimentos circulares, comportamento mais marcante na condição de baias coletivas, representando cerca de $1,74 \%$ do tempo de observação, ao passo que para o sistema de alojamento em baias individuais verifica-se a porcentagem de $0,69 \%$, devido à própria restrição de liberdade de movimento e exploração do meio.

$\mathrm{O}$ acesso dos animais ao bebedouro foi determinado pela necessidade hídrica diária. A ida ao bebedouro ou à "chupeta" representava exclusivamente uma atividade normal dos animais. Constata-se que o tempo despendido ao bebedouro foi de 1,39\% para as matrizes alojadas em baias coletivas e de 2,20\% para os animais em baias individuais.

Em geral, os comportamentos estereotipados foram mais evidentes no sistema de alojamento em baias individuais, representando $14,12 \%$ do tempo total de observação, aproximadamente $3,80 \%$ superior às baias coletivas, em virtude da restrição de espaço nas baias individuais. Resultados semelhantes a estes também foram encontrados por Broom (1991), Mendl et al. (1992) e Vieuille-Thomas et al. (1995). Esta diferença não foi mais acentuada, pelo fato de os animais serem submetidos a um manejo de restrição alimentar, o que possivelmente levou as matrizes alojadas em baias coletivas a expressarem um comportamento natural instintivo, como o ato de fuçar. No entanto, a prática de fuçar piso sólido sem que haja substrato (cama), evidenciando a necessidade de explorar o ambiente na busca por alimento, caracteriza-se como uma estereotipia, que neste caso apresentou valor de 7,99 e 2,43\% para baias coletivas e individuais, respectivamente.

As interações sociais foram facilitadas no alojamento em baias coletivas, onde era permitido aos animais maior contato e liberdade de movimento, verificando-se 5,67\% do tempo de análise. Para as baias coletivas, a possibilidade de contato estava restrita apenas ao animal vizinho. Desta forma, observa-se $3,36 \%$ do total dos comportamentos avaliados.

As interações agressivas foram pouco evidentes, ou praticamente irrelevantes em uma condição média (Tabela 4). Este acontecimento pode ser explicado pelo fato de os animais permanecerem agrupados em baias coletivas até o momento da inseminação, o que possibilitou o estabelecimento de uma hierarquia social organizada e ampliou o grau de conhecimento entre os animais, e, quando reagrupados, não se observaram problemas sociais, tanto nas baias coletivas quanto nas individuais (Van de Burgwal, 1990; Olsson \& Svendsen, 1995; Spoolder et al., 1996).

De acordo com Fraser \& Broom (1997), outro momento crítico ao aumento da agressividade entre os animais seria no arraçoamento, pela disputa por comida, nos cochos ou no chão, porém, por se tratar de um sistema de fornecimento de ração controlado, uma vez ao dia, as observações comportamentais entre 7 e $8 \mathrm{~h}$ foram desconsideradas.

Verifica-se, na Tabela 5, que para postura deitado na posição lateral, em ambos os sistemas de alojamento, a porcentagem do tempo de permanência nesta posição é muito próximo, $25,46 \%$ para baias individuais e $25,23 \%$ para baias coletivas, a exemplo do que acontece com a inatividade dos animais, em razão destes comportamentos estarem associados aos demais comportamentos apresentados na Tabela 4. 
Tabela 5 - Freqüência e porcentagem média da variação comportamental de postura das matrizes alojadas em baias individuais e coletivas

\begin{tabular}{lccc}
\hline & \multicolumn{3}{c}{ Sistema de alojamento } \\
\cline { 2 - 4 } Freqüência & Baias individuais & Baias coletivas & Total \\
(\%) & & & \\
\hline Postura & & & 198 \\
\hline Deitar na posição ventral & 105 & 93 & 22,92 \\
& 12,15 & 10,76 & 438 \\
Deitar na posição lateral & 220 & 218 & 50,69 \\
& 25,46 & 25,23 & 184 \\
Em pé & 68 & 116 & 21,30 \\
& 7,87 & 13,43 & 1 \\
Ajoelhar & 1 & 0 & 0,12 \\
& 0,12 & 0,00 & 43 \\
Sentar & 38 & 5 & 4,98 \\
& 4,40 & 0,58 & 100,00 \\
Total & 432 & 532 & \\
& 50,00 & & \\
\end{tabular}

Os animais assumem a posição deitados ventralmente em $10,76 \%$ dos casos nas baias coletivas e $12,15 \%$ nas individuais, ao passo que a permanência das matrizes em pé, representando o momento de deslocamento dos animais nas baias coletivas e a mudança de postura nas individuais, apresenta valores de $13,43 \%$ para as baias coletivas e de $7,87 \%$ para as individuais, evidenciando-se a maior disponibilidade de espaço no tratamento baia coletiva.

A permanência dos animais na posição sentada é mais evidente nas baias individuais, $4,40 \%$ do total analisado e de $0,58 \%$ para as baias coletivas. A postura ajoelhada não foi registrada na condição de baias coletivas e apresentou reduzida porcentagem para as baias individuais, cerca de $0,12 \%$, possivelmente por se tratar de uma postura de transição.

\section{Conclusões}

$\mathrm{O}$ alojamento em baias coletivas foi o que se mostrou mais adequado às condições de conforto e bem-estar animal para matrizes gestantes.

As variáveis meteorológicas (Tbs, ${ }^{\circ} \mathrm{C}$ e h, $\mathrm{kJ} . \mathrm{kg}^{-1}$ ) apontam o sistema de alojamento em baias coletivas como aquele que permitiu melhor condicionamento térmico natural às matrizes em gestação.

Os parâmetros fisiológicos e os índices zootécnicos apresentaram valores mais adequados para o alojamento em baias coletivas, assim como seu reflexo no desempenho da parição dos leitões provenientes das matrizes submetidas a esse tratamento.

Os animais alojados em baias coletivas apresentaram menor incidência de comportamentos resultantes do estresse ambiental, estereotipias e interações agressivas.

\section{Literatura Citada}

ALBRIGHT, L.D. Environment control for animals and plants. St. Joseph: American Society of Agricultural Engineers Michigan, 1990. 453p. (ASAE Textbook, 4).

ANIL, L.; ANIL, S.S.; DEEN, J. Relationship between postural behaviour and gestation stall dimensions in relation to sow size. Applied Animal Behaviour Science, v. 77, n.3, p.173$181,2002$.

ANIL, L.; ANIL, S.S.; DEEN, J. Relationship between postural behavior and gestation stall dimensions in relation to sow size. Applied Animal Behavior Science, v.77, n.3, p.173-181, 2002.

BARB, C.R.; ESTIENNE, M.J.; KRAELING, R.R. et al. Endocrine changes in sows exposed to elevated ambient temperature during lactation. Domestic Animal Endocrinology, v.8, p.117-1127, 1991.

BAUER, J.; HOY, S. Zur häufigkeit von rangordnungskämpfen beim ersten und wiederholten zusammentreffen von sauen zur gruppenbildung. KTBL-Schrift, v.418, p.181-187, 2002.

BROOM, D.M. Animal welfare: concepts and measurement. Journal of Animal Science, v.69, n.10, p.4167-4175, 1991.

BROWN-BRANDL, T.M.; EIGENGERG, R.A.; NIENABER, J.A. et al. Thermoregulatory profile of a newer genetic line of pigs. Livestock Production Science, v.71, p.253-260, 2001.

BUFFINGTON, D.E.; COLAZZO-AROCHO, A.; CATON, G.H. Black globe humidity comfort index (BGHI) as comfort equation for dairy cows. Transaction of the ASAE, v.24, n.4, p.711$714,1981$.

CAVALCANTI, S.S.; BARBOSA, A.S.; SAMPAIO, I.B.M. Efeito da duração do parto na incidência de leitões natimortos. Arquivos da Escola de Veterinária da UFMG, v.3, n.1, p.9-43, 1979.

CLARK, L.K.; LEMAN, A.D. Factors that influence litter size in pigs: Part 1. Pig News and Information, v.7, p.303-310, 1986.

CURTIS, S.E.; BACKSTROM, L. Housing and environmental: Influences on production. In: LEMANN, A..D.; STRAW, B.E.; MENGELING, W.L. (Eds.) Disease of swine. 7.ed. Ames: The Iowa State University, 1992. p.884-900.

FLORES, B.; CANTLEY, T.C.; MARTIN, M.J. et al. Effect of elevated ambient temperatures on puberty in gilts. Journal of Animal Science, v.67, p.779-784, 1989.

FRASER, A.F.; BROOM, D.M. Farm animal behaviour and welfare. 3.ed. London: Baillière Tindall, 1990. 437p.

FRIEND, D.W.; CUNNINGHAM, H.M.; NICHOLSON, J.W.G. The duration of farrowing in relation to the reproductive performance of Yorkshire sows. Canadian Journal of Medicine Science, v.26, n.6, p.127-130, 1962.

LOVE, R.J.; EVAN, G.; KLUPIEC, C. Seasonal effects on fertility in gilts and sows. Journal of Reproduction Fertility, v.2, suppl.1, p.191-206, 1993

LOVE, R.J.; KLUPIEC, C.; THORNTON, E.J. et al. An interaction between feeding rate and season affects fertility of sows. Animal Reproduction Science, v.39, p.275-284, 1995.

MANNO, M.C.; OLIVEIRA, R.F.M.; DONZELE, J.L. et al. Efeito da temperatura ambiente sobre o desempenho de suínos dos 15 aos $30 \mathrm{~kg}$. Revista Brasileira de Zootecnia, v.34, n.6, p. 1963-1970, 2005.

MENDL, M.; ZANELLA, A.J.; BROOM, D.M. Physiological and reproductive correlates of behavioural strategies in female domestic pigs. Animal Behaviour, v.44, p.1107-1121, 1992.

MORES, N.; SOBESTIANSKY, J.; WENTZ, I. et al. Manejo do leitão do nascimento até o abate. In: SOBESTIANSKY, J.; WENTZ, I.; SILVEIRA, P.R.S. et al. (Eds.) Suinocultura intensiva. Concórdia: Embrapa CNPSA, 1998. p.135-161.

MOUNT, N.C.; SEABROOK, M.F. A study of aggression when group housed sows are mixed. Applied Animal Behaviour Science, v.36, n.1, p.377-383, 1993. 
MOURA, D.J.; NÄÄS, I.A.; SILVA, I.J.O. et al. The use entalpy as a thermal comfort index. In: LIVESTOCK ENVIRONMENT, 5., 1997, St. Joseph. Proceedings. St. Joseph: ASAE, 1997. v.1, p.242-248.

MUIRHEAD, M.; ALEXANDER, T. Managing pig health and the treatement of disease. Sheffield: 5Mentreprises, 1997. $608 \mathrm{p}$.

NOBLET, J.; DOURMAD, J.Y.; DIVIDICH, J. et al. Effect of ambient temperature and adition of straw or alfafa in the diet on energy metabolism in pregnant sows. Livestock Production Science. v.21, p.309-324. 1989

NUNES, C.G.V.; COSTA, E.P.; OLIVEIRA, R.F.M. et al. Efeito do acondicionamento térmico ambiental sobre o desempenho reprodutivo da fêmea suína. Revista Brasileira de Zootecnia. v.32, n.4, p.854-863, 2003.

O'CONNELL, N.E.; BEATTIE, V.E.; MOSS, B.W. Influence of replacement rate on the welfare of sows introduce to a large dynamic group. Applied Animal Behaviour Science, v.85, n.1-2, p.43-56, 2004.

OLSSON, A.; SVENDSEN, J. Mixing of sows and gilts: problems and routines. Lund: Swedish University of Agricultural Sciences, 1995. p.123-136. (Report, 96)

PELTONIEMI, O.A.T.; LOVE, R.J.; HEINOMEN, M. et al. Seasonal and management effects on fertility of the sow: a descriptive study. Animal Reproduction Science, v.55, p.47-61, 1999.

PEREIRA, A.R.; ANGELOCCI, L.R.; SENTELHAS, P.C. Agrometeorologia: fundamentos e aplicações práticas. Guaíba: Agropecuária, 2002. 478p.

PEREZ Y PEREZ, P.; PEREZ GUTIEREZ, J.F. S u m mer infertility of swine stock in Spain. Luxemburg: Commission of the European Communities, 1987. p.25-28.
RUDKIN, C.; STEWART, G.D. Behaviour of hens in cages: a pilot study using video tapes. A Report for the Rural Industries Research and Development Corporation, v.40, n.477, p.102, 2003.

STATISTICAL ANALYSIS SYSTEM - SAS. Statistical analysis system: realease 6.08 (software). Cary: SAS Institute, 1992. 620 p.

SILVA, I.J.O. Sistemas naturais e artificiais do controle do ambiente - climatização. In: SILVA, I.J.O. (Ed.) Ambiência e qualidade na produção industrial de suínos. Piracicaba: Fundação de Estudos Agraários Luiz de Queiroz, 1999. p.81-101.

SILVA, R.G. Tópicos especiais em construções rurais e ambiência: notas de aula. Campinas: FEAGRI, 1995. 98p.

SPOOLDER, H.A.M.; BURBIDGE, J.A.; EDWARDS, S.A. et al. Social recognition in gilts mixed into a dynamic group of 30 sows. Animal Science, v.62, n.1, p. 630, 1996.

VAN DER LENDE. Embryo mortality and prolificacy in the pig. In: COLE, D.J.A.; WISEMAN, J.; VARLEY, M.A. (Eds.) Principles of pig science. Longhborough: Nothingan University Press, 1994. 472p.

VIEIRA, H.P.; VIEIRA, R.P. Definition of the summer infertility problem in the pig. Luxemburg: Commission of the European Communities, 1987. 35p.

VIEUILLE-THOMAS, C.; LE PAPE, G.; SIGNORET, J.P. Stereotypies in pregnant sows: indication of influence of the housing system on the patterns expressed by the animals. Applied Animal Behaviour Science, v.44, n.1, p.19-27, 1995.

YAN, P.S.; YAMAMOTO, S. Relationship between thermoregulatory responses and heat loss in piglets. Journal of Animal Science, v.71, n.10, p.5005-509, 2000. 